\title{
Annual Cycles of Avian Migrants in Predicting the Carrying Capacity of a Marine Ecosystem
}

\author{
Belen T. Lumeran \\ Faculty, Science Department, AMA International University-Bahrain
}

\begin{abstract}
The seasonal cycles of migratory birds in predicting the carrying capacity of a marine ecosystem in the Kingdom of Bahrain was conducted. This study specifically determines the total number of avian migrants at varying months and annual cycles; find out significant difference in the total number of non-volant avian migrants at different annual cycles; and predict the carrying capacity (M) of the marine ecosystem using a logistic model. Results showed that the total number of avian migrants is high during the month of December in 2013 (642), and low in January 2011 (516). Similarly, the total number is high in cycle 3 (2013) with a total of 2,720 non-volant avian migrants while low in cycle 1 (2011) with 2,242. Statistical analysis using ANOVA revealed significant difference in the number of avian migrants at varying annual cycles. Avian migrants preferred the marine ecosystem as their temporary habitat during their annual cycles which provides various resources. The carrying capacity (M) of the identified marine ecosystem can be predicted using a logistic model. Assuming that the population growth rate of avian migrants is low $(r=0.4)$, and $\mathrm{M}$ $=1000$, results depicted that the fraction of unused carrying capacity can still support the growing population. This is evidenced by the $45 \%$ unused fraction of the carrying capacity during the terminal cycle in 2013 . Results further predict that the future carrying capacity will be reduced. Hence, the annual cycles of avian migrants predicts the carrying capacity of the identified marine ecosystem using a logistic model.
\end{abstract}

Keywords: Avian migrants, Carrying capacity, Marine ecosystem, Logistic model

\section{INTRODUCTION}

The coastal zone and the marine environment in the Kingdom of Bahrain support a range of coastal and sea birds. The area is richly endowed with important resources which served as hosts to seabird migrants. The annual cycle of bird migration had been observed in the coastal and marine areas. The coastal and marine ecosystems provide a wide range of habitat [1] for the seasonal migration of birds. Migratory birds are visitors in the area en route to their destinations [2]. The local abundance and spatial distribution of migratory birds is attributed to various factors [3]. Migration as a behaviour allows exploitation of seasonally productive environment $[4,5]$. Bird migration is marked by cyclical patterns in response to changes in food availability [6], habitat or weather. Migration is typically a long established route over a very long distance [7]. However, these animals remain flexible to environmental conditions [8] in terms of food supply [9] and temperature [10] which vary annually. Migrant species find the marine environment as the best ecological condition for feeding [11,12], breeding [13-15], and raising their young. The temperature changes in the coastal and marine environments [16] are favourable for the many migratory birds other than its natural inhabitants. Avian migration is a consequence of seasonal changes in population density of a particular area [17]. The clumped spatial distribution of migratory birds showed habitat preference [18].

Carrying capacity is an ecological index which expresses the relationship between the population and the natural environment [19]. This is based on the premise that a given habitat can support a population for a period of time. Likewise, the maximum population that can be

supported depends on the level of resources over a particular period of time [20]. Hence, annual fluctuation in density is an estimate of carrying capacity using a logistic model [21]. The maximum number of avian migrants the habitat can support for the entire season determines the carrying capacity [22]. The assumption on the limit of the number of individuals that can be supported at a given level of consumption without considering the environment reduces future carrying capacity.

Hence, this research undertaking was conducted to determine the seasonal cycles of avian migrants in predicting the carrying capacity of a marine ecosystem in the Kingdom of Bahrain. Specifically, this study was conducted to find out the total number of non-volant avian migrants at varying annual cycles; determine significant difference in the number of non-volant avian migrants at different annual cycles; and predict the carrying capacity (M) of the marine ecosystem based on the population of avian migrants using logistic model.

\section{RESEARCH METHOD}

This is a descriptive-experimental research which made use of the number of avian migrants in the identified marine ecosystems at varying months for three annual cycles. This then determined the over-all carrying capacity using a logistic model which assumed a low density growth rate, $r=0.4$ and carrying capacity, $\mathrm{M}=1000$.

Field monitoring of aerial temperature was done simultaneously during the field sampling once every month of each sampling month.

A regular or systematic sampling with fifteen established sampling units was used to determine the 
number of avian migrants in the sampled marine ecosystem. An imaginary transect line measuring 10 meters and separated by a distance of 1 meter were established perpendicular to the end-to-end stretch of the identified area where the non-volant migratory birds were mostly clumped. Visual counting of non-volant avian migrants was done 5.0 meters offshore using a focusing digital camera pixel and electronic stopwatch.

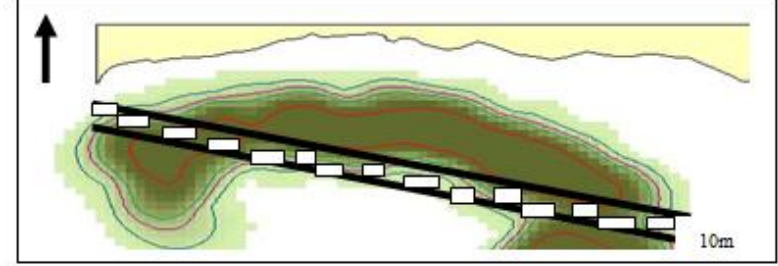

Fig. 1 Established imaginary transect line

A. Determination of Carrying Capacity (M) and Statistical Analysis

The use of a logistic model [21] as a predictor of carrying capacity of the identified marine ecosystems utilized both the population size and the fraction of unused carrying capacity. The population size that the environment can support is based on the population size $\mathrm{Pt}$, in time period $\mathrm{t}$, and carrying capacity $\mathrm{M}$, is the population size. Thus, the unused fraction is expressed as $\frac{1-P t}{M}$. The fraction of the carrying capacity that is used as $\frac{P t}{M}$. It was assumed that the growth rate, $r=0.4$ determined the population size, $\mathrm{Pt}$ in relation to carrying capacity, $\mathrm{M}$. The formula $\mathrm{Pt}+1-\mathrm{Pt}=0.4 \times \mathrm{Pt} \times\left[1-\frac{P t}{M}\right]$ is used to determine the carrying capacity of the sampled area with $\mathrm{M}=1000$.

The use of Analysis of Variance (ANOVA) determined significant difference in the number of non-volant migratory birds at different annual cycles.

\section{RESULTS AND DISCUSSION}

A. $\quad$ Total Number of Migratory Birds for Three (3) Annual Cycles, 2011-2013

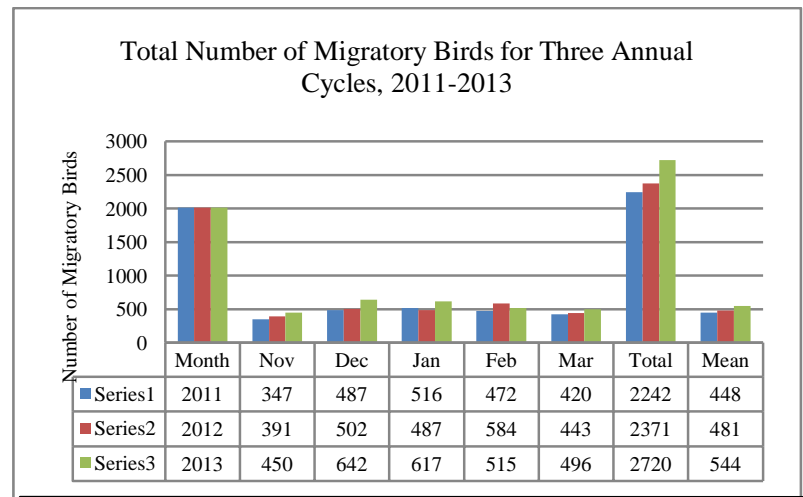

Fig. 1 Total number of migratory birds for three annual cycles
As presented in Fig. 1, the total number of migratory birds is high during the month of December 2013 (642), followed by February in 2012 (548), and in January 2011 (516). Of the three (3) annual cycles, the total number of avian migrants is highest in 2013 (Total $=2720$ ) with a mean $=544$, followed by in $2012($ Total $=2371)$, mean $=$ 481 and lowest in 2011 (Total = 2242), mean $=448$. Results imply that the coastal and marine ecosystem in the Kingdom of Bahrain is productive in marine resources. This is evident of the clump spatial distribution which showed habitat preference [18].

Table 1. Result of Analysis of Variance (ANOVA) on the number of avian migrants at varying annual cycles

\section{SS df MS F-value p-value}

Between 24,461.733 2 12,230.867 $20.019 \quad 0.000^{*}$

Groups

Within $\quad 5,866.335 \quad 12488.861$

Groups

Total 30,328.068

*The mean difference is significant at .05 level.

Statistical analysis using ANOVA showed significant difference in the number of migratory birds at varying annual cycles. Result implies that the number of migratory birds increases every annual cycle. This can be attributed to the milder temperature in the area with a mean temperature range of $15.1^{\circ} \mathrm{C}$ to $30^{\circ} \mathrm{C}$ during the study periods. It was observed that the coastal and marine ecosystems respond to seasonal variations which include both the biotic and abiotic factors. The temperature changes in the coastal and marine environment are favourable for many migratory birds [16]. However, these animals are flexible to environmental conditions [8]. This then characterized the benefits of the transient inhabitants like the migratory birds as depicted in this study. However, actual temperature monitoring and recording to support the effects of global climate change to marine life were not identified.

B. Predicted Carrying Capacity (M) based on the Population of Avian Migrants for Three (3) Annual Cycle, 2011-013

Table 2. Percent (\%) Unused and Used Fraction of the Carrying Capacity (M)

\begin{tabular}{lcccccc}
\hline Month & \multicolumn{5}{c}{ Annual Cycle } \\
& $\begin{array}{l}2011 \\
\text { (in \%) }\end{array}$ & \multicolumn{2}{c}{2012} & 2013 \\
& (in \%) & \multicolumn{2}{c}{ (in \%) } \\
November & 65 & 35 & 61 & 39 & 55 & 45 \\
December & 51 & 49 & 50 & 50 & 36 & 64 \\
January & 48 & 42 & 51 & 49 & 38 & 62 \\
February & 53 & 47 & 45 & 55 & 48 & 52 \\
March & 58 & 42 & 56 & 44 & 50 & 50 \\
Weighted & & & & & & \\
Mean & 55 & 45 & 52 & 48 & 45 & 55 \\
\hline
\end{tabular}

Table 2 shows the percent (\%) unused and used fraction of the carrying capacity (M) based on the population of migratory birds. The unused fraction of 
carrying capacity is high in November $(65 \%)$ and low in January $(48 \%)$ in cycle 1 (2011); November $(61 \%)$ and February (45\%) in cycle 2 (2012); December (64\%) and November $(45 \%)$ in cycle 3 . It can be noted that during the given times, the mean percent of unused fraction of carrying capacity is inversely proportional to the used fraction of the carrying capacity. Based from this result, it can be inferred that the unused fraction of carrying capacity decreases as the used fraction increases. The number of migratory birds significantly increases at varying annual cycles (Table 1), hence, a fluctuation in population size. This implies an estimate to carrying capacity [21] which determines the relationship of population, natural environment, and the available resources of the area. Further, it can be predicted that the population size of avian migrants will be almost to carrying capacity. This can be further interpreted that the growth rate has fallen to $0.4 \%$ per time period with the assumption that $\mathrm{r}=0.4$ and $\mathrm{M}=1000$. At this point, the available resources of the area can only support the given population for the entire season [22] which determines the carrying capacity of this particular marine ecosystem.

\section{CONCLUSION}

The coastal and marine ecosystems in the Kingdom of Bahrain are endowed with resources for non-volant avian migrants, thus increasing the population at varying annual cycles. The number of avian migrants varies significantly at differently annual cycles which determine the unused fraction of carrying capacity (M). Using a logistic model predicts the carrying capacity of the identified marine ecosystem assuming a low density population growth rate, $\mathrm{r}=0.4$ and $\mathrm{M}=1000$. Hence, the available resources can still support the future avian migrants, however, reducing the future carrying capacity.

\section{REFERENCES}

[1] T. R. Chesser, Bird Conservation International, Cambridge Journals, vol. 4, Special Issue 2-3, pp. 91-107, 1994.

[2] Marine Life. Princetown Center for Coastal Studies, 2012. [Online]. Available: http:coastalstudies.orgwhat-we-do/stellwagenbank/marine-life.htm

[3] T. Alerstam and A. Hedenstrom, The development of bird history, Journal of Avian Biology, vol. 29, No. 4, pp. 343-369, 1998.

[4] T. R. Chesser, Further perspective on the breeding distribution of migratory birds, Journal of Animal Ecology, vol. 67, pp. 69-77, 1998

[5] S. Akesson and A. Hedenstrom, How migrants get there: Migratory performance and orientation, BioScience, vol. 57, No. 2, pp. 123133.

[6] State of the Gulf Marine Report Coastal Ecosystem and Habitat, 2012. [Short Communication]

[7] S.R. Clark, T.B. Ryder, J.F. Saracco and P. P. Mama, Assessing migratory connectivity for a long-distance migratory bird using multiple intrinsic markers, Ecological applications, In press, 2013. [Online]. Available: http//dx.doi.org/10.1890/13-1091.1

[8] Bird migration,2013. [Online] Available: http://newworldencyclopedia.org/entry/Bird_migration

[9] J.E. Braithwaite, J.J. Meeuwig and C.S. Jenner, Estimating cetacean carrying capacity based on spacing behaviour, PLoS ONE, vol.7, No. 12:e51347, doi:10.1371/journal.pone.0051347, 2012.

[10] G. Cox, "Bird migration and global change", Journal of Migratory Birds, USA: Island Press, 2010.

[11] J.I. Ellis, S.I. Wilhelm and A. Heddi, "Mortality of migratory birds from marine commercial fisheries and offshore oil and gas production in Canada", Avian Conservation Ecology, vol. 29, No. 2, p. 4, 2013

[12] K. Ashok and M. Srivastava, "The biodiversbirdsity at Sandi Bird Sanctuary, Hardoi with special reference to migratory", 2013. [Online). Available: http://www.sciencebeingjournal.com/octajournal-environmental-research/biodiversity

[13] C. Exo and O. Huppop, "Birds and offshore wind farms: A hot topic in marine ecology, Wadder Study Group Bulletin, vol. 100, pp. 50$53,2013$.

[14] J. Faaborg and R. Holmes, "Conserving migratory land birds in the New Word: Do we know enough?”, Ecological Society of America, vol. 29, No. 2, pp. 394-418, 2013.

[15] M. Someveille, A. Manica, SHM. Buchart, and ASL. Rodrigues, "Mapping global diversity patterns for migratory birds", PLoS ONE, vol. 8, No. 8: e70907, doi:10.1371/journal.pone.0070907, 2013.

[16] V. Kenning, R. Truelly, J.R. Kelypas, J. Cowan, and S.R. Hare, "Coastal and marine ecosystems and global change", 2012.

[17] M.R. Wernard, J.M. Marquenie, H.B. Poot, J.H. Ens, M.A. De Vriess and H. Donner, "Green light for nocturnally migrating birds", Ecology and Society, vol. 13, No. 2, p. 47, 2008. [Online]. Available: URL:http://www.ecology and society.org/Vol. 13/1552/art 47/

[18] O.. Hungarica, "Local abundance and spatial distrubtion of some migratory birds during post-breeding period", vol. 20, Issue 1, pp. 50-58, ISSN (online) 2061-9588, doi:10.2478, 2013.

[19] V.D. Abernethy, "Carrying capacity: The tradition and policy implications of limits", Science and Environmental Politics (ESEP), VI, Issue 1, 9:18, 2001.

20] D. Ayllon, A. Almodovar, G.G. Nicola, I. Parra and B. Elvin, "Modelling carrying capacity dynamics for the conservation and management of territorial salmonids", Fisheries Research, pp. 134136, 2012.

[21] D.Q. Nykamp, J.L. Cornette and R.A. Ackerman, "Environmental capacity from math insight", 2013. [Online]. Available: http://Math insight.org/environmental_carrying capacity.

[22] M.G. Zhen, Z. Ziao, H.W. Tian, Y.W. Kai and P. Eule, "Effetcs of vegetative changes on the carrying capacity of migratory shorebirds in a newly formed wetland, Yangtze River, Estuary, China", Zoological Studies, vol.48, No. 6, pp. 769-779, 2009. 